\title{
EFFECT OF TEPA, SHIKONIN AND ECDYSONE ON THE ACID PHOSPHATASE IN THE LARVAE OF AEDES AEGYPTI
}

\author{
L. J. RASHAN, S. N. H. NAQVI*, N. S. GORGEES AND S. SHAREEF \\ Department of Biology, College of Science, Mosul L'niversity, Mosul, IRAQ
}

Received for publication July 15, 1977, in revised form December 12, 1977 and

in re-revised form February 20, 1978

\begin{abstract}
Effect of tepa, shikonin and ecdysone was studied on the activity of acid phosphatase by biochemical and histochemical methods. Tepa and shikonin (chemosterilants) inhibited the enzyme activity while ecdysone had no effect. These findings have been discussed in the present paper.
\end{abstract}

The literature is replete with the papers on the inhibition of enzymes by various pesticides. Among them, inhibition of phosphatases has also been reported (3, 10-16, 20). However, to the best of our konwledge, no report is available on the inhibition of acid phosphatase by chemosterilants. Therefore, work on this aspect of chemosterilants was carried out. For this purpose, a standard chemosterilant (tepa) and a prospective chemosterilant (shikonin) were selected. A hormone (ecdysone) which is metamorphosis regulator, was also taken to study its effect on the enzyme and compare it with that of chemosterilants and control.

The testing was done on 4th instar larvae of Aedes aeg ypti (Rockefeller susceptible strain). Both biochemical and histochemical experiments were done on treated 4th instar larvae and control larvae. The 4th instar was selected because it was more susceptilbe to these compounds (19). The findings have been presented and discussed here.

\section{MATERIALS AND METHODS}

Insect Material: A standard strain of Aedes aegypti (Rockefeller susceptible strain) was obtained by the courstey of Dr. A. W. A. Brown, Director, Pesticide Research Centre, Michigan State University, USA and was reared under controlled conditions in the Biology Department. Fourth instar larvae of this strain were used during the experiments.

Chemicals for Trearment: Shikonin (1) was obtained from Dr. M. Afzal of the Chemistry Department of this university. Tepa was obtained by the courtsey of Dr. A. B. Borkovec, Director, Entomology Research Division, USDA, Beltsville, Md. USA. Ecdysone was obtained from Dr. Jan Koolman, Institüt für Physiologische-Chemie, 3550 Marburg, W. Germany. One percent solutions of these chemicals were prepared in ethanol as stock and then diluted with distilled water, according to the dose required for treatment. The stock solutions were stored in refrigerator.

* Present address: Head, Department of Biological Sciences, Maiduguri University, PMB 1069, Maiduguri, Nigeria. 
Method of Treatment: One hundred 4th instar larvae of uniform size and age were taken in each beaker in $200 \mathrm{ml}$ distilled water. Dilutions were made from the stock solutions and mixed in the beakers, so as to give a concentration of $7 \mathrm{ppm}$ for shikonin, $35 \mathrm{ppm}$ for tepa and $50 \mathrm{ppm}$ for ecdysone, after making the volume up to 250 $\mathrm{ml}(19)$.

The larvae were exposed to the solution for $24 \mathrm{hrs}$ and then transferred to fresh water. Each experiment was carried out in duplicate and a control was kept simultaneously. The dead larvae were discarded while those alive and moribund were stored in freezer, in distilled water for biochemical estimation and in $1: 1$ acetone + alcohol for histochemical localization.

Biochemical Estimation: Determination of acid phosphatase activity was done in the treated and control larvae, simultaneously, according to Naqvi et al. (8).

Histochemical Localization: Histochemical localization was done by two methods, both in control and the treated larvae. The methods followed were those of Ashrafi and Fisk (2) and Gomori (6). The two methods were used for the sake of confirmation. The incubation time in the present experiments was $30 \mathrm{~min}$ for the former and $1 \mathrm{hr}$ for the later method.

\section{RESULTS}

\section{Histochemical Localization:}

\section{(Ashrafi and Fisk Method)}

Control (Fig. 1): Acid phosphatase activity is distinct and strong in control. The figure indicates strong activity in caecum $(\mathrm{C})$ and moderate activity in ciliated border $(\mathrm{CB})$ of the midgut.

Shikonin (Fig. 2): In the case of shikonin there is great degeneration or distortion of the tissue and the activity is strong in the lumen $(\mathrm{L})$. There is patchy activity also perhaps due to degeneration of tissue. This degeneration effect may be due to the poisoning or toxic effect of the compound.

Ecdysone (Fig. 3): In this case the section shows moderate activity in caseum (C) and some activity in midgut.

Tepa (Fig. 4): This section shows that the acid phosphatase activity is more inhibited by tepa but the distortion of tissue is lesser than shikonin. The activity is patchy and limited to caecum $(\mathrm{C})$.

\section{(Gomori Method)}

Control (Fig. 5): In this case also the acid phosphatase activity is sharp and

TABLE 1. The effect of chemicals on the activity of acid phosphatase (average value of 5 experiments with S.D.)

\begin{tabular}{lr} 
Chemical & $\begin{array}{l}\text { Number of micromoles } \\
\text { released/mgm fresh tissu }\end{array}$ \\
\hline Shikonin & $18 \pm 2.1$ \\
Tepa & $14 \pm 1.2$ \\
Ecdysone & $76 \pm 1.9$ \\
Control & $80 \pm 3.1$
\end{tabular}


strong in caecum $(\mathrm{C})$ and negligible in forgeut (FG). No activity is present in the body wall and muscles.

Shikonin (Fig. 6): This section also shows much distortion. Although there are some patches of activity but it is not clear to which part it belongs.

Ecdysone (Fig. 7): The section shows strong acid phosphatase activity in the caecum (C) but negligible in midgut (MG).

Tepa (Fig. 8): The section shows degeneration of tissue to some extent but extreme inhibition of the enzyme activity. However, lumenal activity (L) can be seen in this section.

\section{Biochemical Estimation:}

The biochemical estimation of acid phosphatase in the treated and control

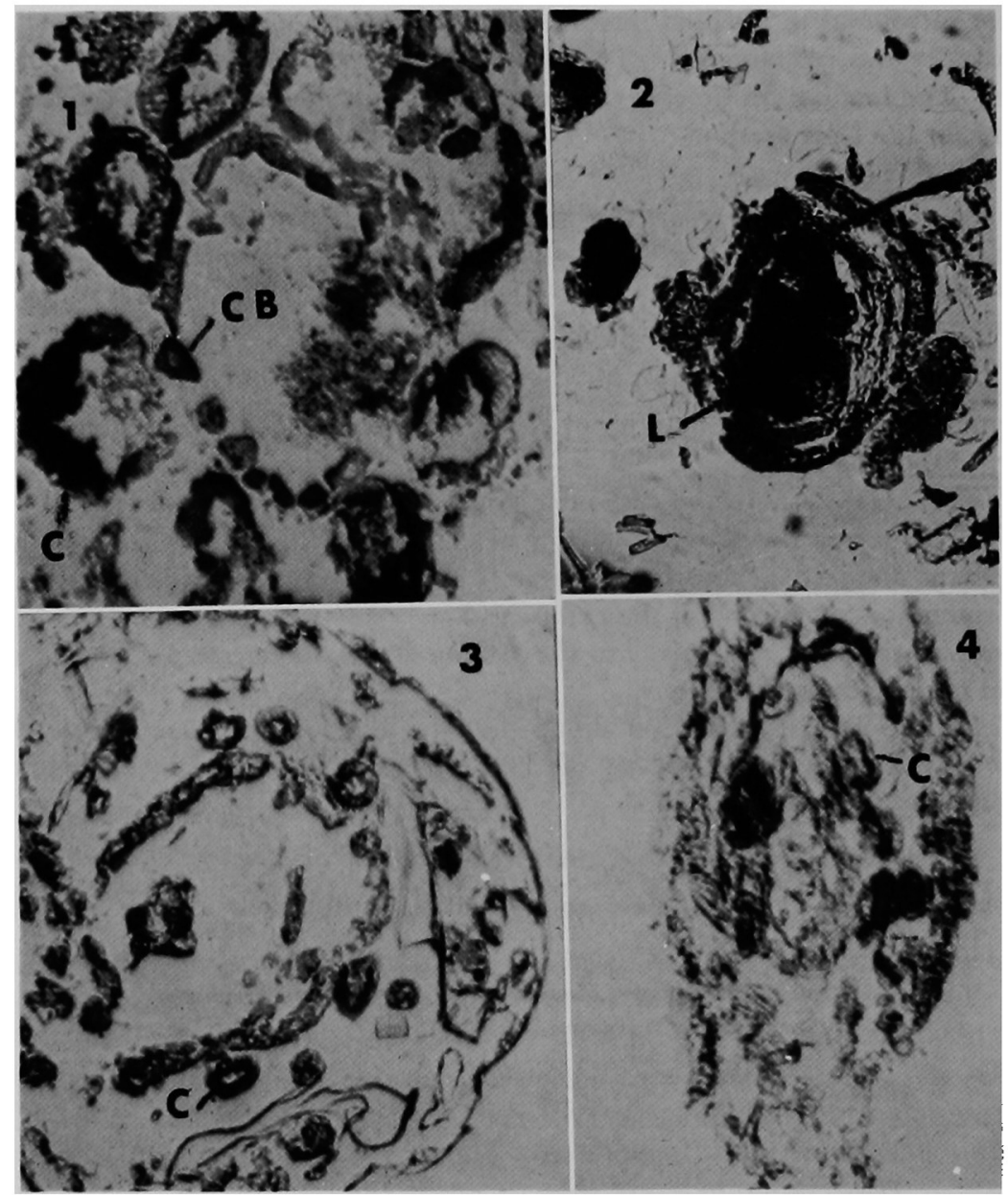

FIGs. 1-4. Acid phosphatase activity. Ashrafi and Fisk Method. Fig. 1. Control. $\times 10$ Fig. 2. Shikonin-treated larvae. $\times 10 \quad$ Fig. 3 . Ecdysone-treated larvae. $\times 4$ Fig. 4. Tepa-treated larvae. $\times 4$ C: caecum, CB: ciliated border, L: lumen. 


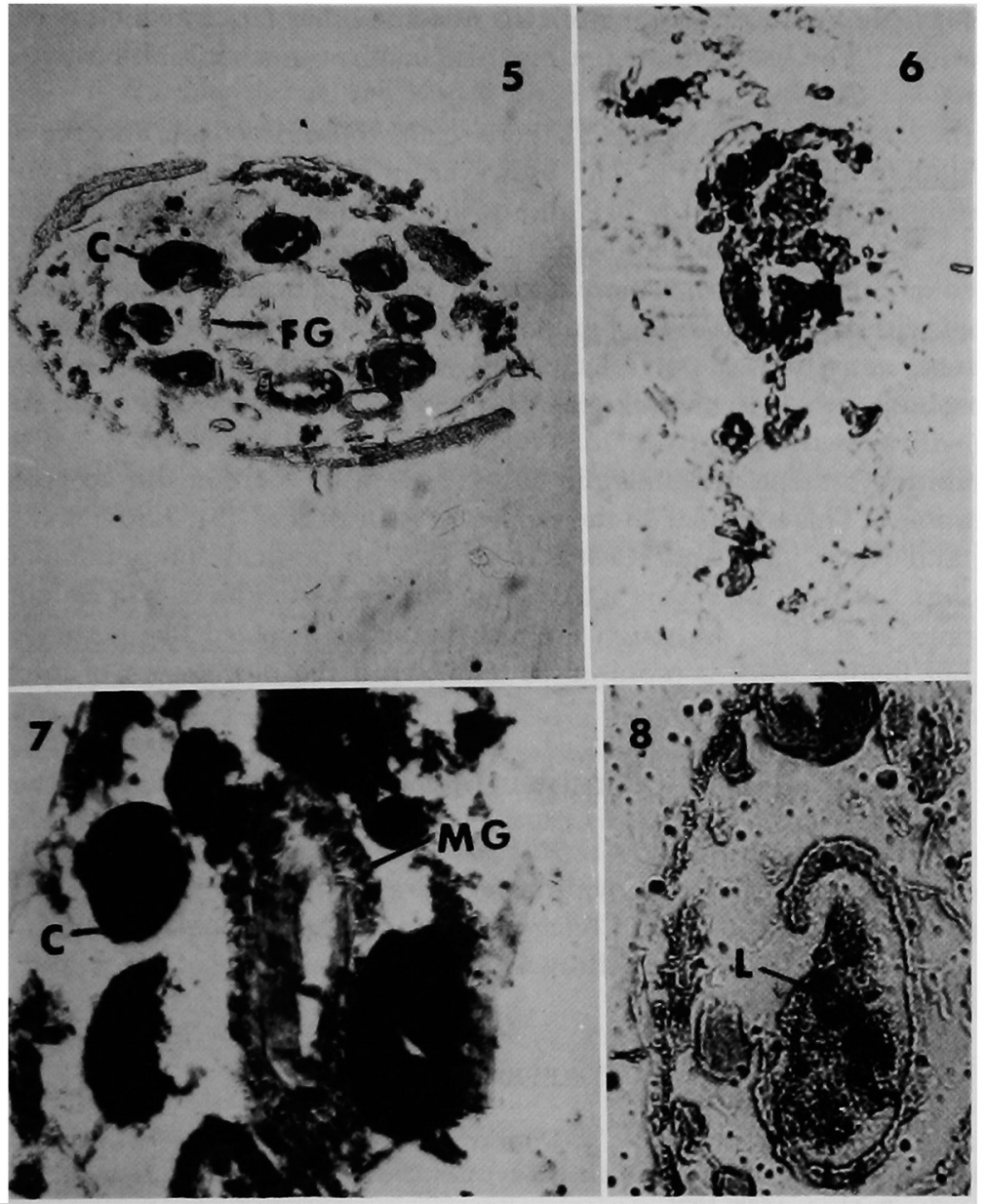

FIgs. 5-8. Acid phosphatase activity. Gomori Method. FIG. 5 . Control $\times 4$ FIG. 6 . Shikonintreated larvae. $\times 4$ Fig. 7. Ecdysone-treated larvae. $\times 10 \quad$ Fig. 8 . Tepa-treated larvae. $\times 10$ $\mathrm{C}$ : caecum, FG: foregut, MG: midgut, L: lumen.

larvae also revealed inhibition of this by shikonin and tepa while ecdysone showed no effect and the activity in the control and ecdysone treated larvae was almost equal (Table 1).

\section{DISCUSSION}

The histochemical localization in the control (Figs. 1,5) indicates strong acid phosphatase activity in the caecum $(\mathrm{C})$ but slight activity in the mid-gut. Similar reports are available for other insects $(2,17)$. The larvae which were treated with tepa and shikonin showed considerably low activity. However, in the case of acid phosphatase the inhibition with tepa was more than shikonin, in contrast to the report of Gorgees et al. for alkaline phosphatase. This may be either due to degene- 
ration of cells or greater poisoning of cells or some other factor, which needs further investigation. The biochemical findings also confirm more inhibition by tepa than shikonin.

In the case of ecdysone (Fig. 3) there seems to be no effect, and the activity is almost equal to the control (Fig. 1). However, in Figure 7, there seems to be slightly more precipitation. Probably it is due to higher magnification as compared with Figure 5. The observations indicate that the technique used by Ashrafi and Fisk (2), based on Burstone's (5), is more differentiative. The acid phosphatase has been correlated with absortion and assimilation $(8,9,17)$. Perhaps due to this the acid phosphatase activity was not effected by ecdysone which regulates growth and metamorphosis, whereas, the alkaline phosphatase was effected because it has correlation with growth $(4,7,8)$.

Inhibition by tepa and shikonin (Figs. 2, 4, 6, 8) is either due to poisoning or degeneration. This is similar to the reports of Ashrafi et al. (3), Naqvi et al. (10-13), Zubairi and Naqvi (20) and Rashid et al. (18) on pesticide-phosphomonoesterase relationship. Almost no report is available on neo-pesticides except Sulaiman (19) and Gorgees et al. (7). Although the neo-pesticides behaved like pesticides in this respect but further work is required to understand the mechanism of inhibition of phosphatases.

\section{ACKNOWLEDGEMENTS}

The authors are grateful to Dr. M. H. Kasim and Dr. Zuhair-Al-Sharook of the Biology Department for providing facilities during the progress of the work. They are also thankful to Dean College of Science, Dr. Farooq-Al-Omari. Special thanks are due to Dr. A. W. A. Brown, Dr. A. B. Borkovec of USA and Dr. Jan Koolman of West Germany.

\section{REFERENCES}

1. Afzal, M. and Tawfeeq, M.: 5,8-Dihydroxy-2-(4-methyl-pent-3-enyl)-1,4-naphthoquinone and its 2-[4-methyl-1-(2-methyl crotonyloxy) pent-3-enyl] analog, from Alkana hirsutissima. J. Chem. Soc. Perkin. 1; 1333, 1975.

2. Ashrafi, S. H. and Fisk, F. W.: Histochemical localization of phosphomonoesterases in the stable fly, Stomoxys calcitrans using naphthol AS-phosphate. Ohio J. Sci. 61; 7, 1961.

3. Ashrafi, S. H., Naqvi, S. N. H., Muzaffar, S. A. and Qureshi, S. A.: Comparative effect of insecticides on the activity of high energy producing enzymes. Pakistan J. Sci. Res. 20; 170, 1968.

4. Ashrafi, S. H., Naqvi, S. N. H. and Qadri, M. A. H.: Alkaline phosphatase in the digestive system of desert locust, Schistocerca gregaria. Ohio J. Sci. 69; 183, 1969.

5. Burstone, M. S.: Histochemical comparison of acid phosphatase with naphthol AS-phosphate. Nat. Cancer Inst. 21; 523, 1958.

6. Gomori, G.: An improved histochemical technique for acid phosphatase. Stain Technol. 25; $81,1950$.

7. Gorgees, N. S., Naqui, S. N. H., Rashan, L. J. and Zakaria, S. J.: Effect of tepa, shikonin and ecdysone on the alkaline phosphatase in the larvae of Aedes aegypti (L). Folia Histochem. Cytochem. $16 ; 51,1979$.

8. Naqui, S. N. H., Ashrafi, S. H. and Qadri, M. A. H.: Quantitative determination of acid and alkaline phosphatase in the digestive system of desert locust. Pakislan J. scient. ind. Res. 10; 204, 1967. 
9. Naqvi, S. N. H., Ashrafi, S. H. and Qadri, M. A. H.: Phosphomonoesterases activity in life cycle stages of Schistocerca gregaria. Can. Ent. 100;649, 1968.

10. Naqvi, S. N. H., Qureshi, S. A. and Muzaffar, S. A.: Studies of in vivo effect of varying doses of insecticides on phosphomonoesterases of desert locust. Folia biol. 10: 410, 1969.

11. Naqvi, S. N. H. ,Zubairi, M. Y. and Rashid, S.: In vivo inhibition of phosphomonoesterases by dimetilan and its metabolites in desert locust. Pak. J. Biochem. 2; 55, 1969.

12. Naqui, S. N. H., Muzaffar, S. A. and Ashrafi, S. H.: Detoxification of DDT and its relation with inhibition of phosphomonoesterases of desert locust. Z. Pflanzenkrank. Pflanzenschutz. 77; $577,1970$.

13. Naqvi, S. N. H., Rashid, S. and Ashrafi, S. H.: The effect of different insecticides on the activity of phosphomonoesterases of Poekilocerus pictus. Pak. J. Zool. 2; 149, 1970.

14. Ogita, Z.: Genetic control of multiple forms of the acid phosphomonoesterases in Musca domestica. J. Jap. Genetics 40; 185, 1965.

15. Oppenoorth, F. J.: Genetics of resistance to organophosphorus compounds and low ali-esterase activity in housefly. Ent. exptl. Appl. 2; 304, 1959.

16. Oppenoorth, F.J. and Asperen, K. van,: Allelic genes in the housefly producing modified enzymes that cause organophosphate resistance. Science $132 ; 298,1960$.

17. Qureshi, S. A., Ashrafi, S. H. and Naqvi, S. N. H.: The distribution of acid phosphatase in the digestive system of desert locust, Schistocerca gregaria. Folia Histochem. Cytochem. 8: 23, 1970.

18. Rashid, S., Roohi, R. A. and Naqvi, S. N. H.: Characterization of acid phosphatase and its relation with insecticide metabolism in Bruchus chinensis. Environ. Qual. Safety 2; 209, 1973.

19. Sulaiman, H. M. S.: Effect of some standard and prospective chemosterilants on the morphology and zymograms of Aedes aegypti (L). M. Sc. Thesis, Mosul University, Mosul, Iraq.

20. Zubairi, M. Y. and Naqvi, S. N. H.: Dimetilan metabolism and its anti-phosphomonoesterase activity in locust. Eniron. Qual. Safety $1 ; 245,1972$. 